\title{
Characterization of indoor bioaerosols from a hospital ward in a tropical setting
}

\author{
*Sudharsanam S ${ }^{1}$, Swaminathan $\mathrm{S}^{2}$, Ramalingam A ${ }^{1}$, Thangavel $\mathrm{G}^{1}$, Annamalai R $\mathrm{R}^{1}$, Steinberg $\mathrm{R}^{1}$, \\ Balakrishnan $\mathrm{K}^{1}$, Srikanth $\mathrm{P}^{1}$
}

1. Sri Ramachandra Medical College and Research Institute, Sri Ramachandra University, Porur, Chennai, Tamil Nadu, 600116, India.

2. National Environmental Engineering Research Institute, CSIR-complex, Taramani, Chennai, Tamil Nadu, 600113, India.

\begin{abstract}
Objectives: Study was conducted to assess whether temporal variation exists in airborne microbial concentrations of a hospital ward (west-Chennai, India) using active and passive methods, and characterise the microorganisms.

Methods: Air samples (duplicates) were collected simultaneously using exposed-plate, impingement (BioSampler) and filtration (personal sampling filter cassette loaded with gelatin filter) methods over different periods of the year. Bacterial plates were incubated at $37^{\circ} \mathrm{C}$ and observed for growth after $48 \mathrm{~h}$; fungal plates were incubated at $25^{\circ} \mathrm{C}$ and $37^{\circ} \mathrm{C}$ and observed upto 7 days. Microorganisms were identified using standard microbiological procedures.

Results: Microbial loads were found to vary with the sampling method. Concentrations of bacteria were higher (exposedplate: 45-150 CFU/plate; impingement: 1.12E +03-1.6856E+05 CFU/m³; filtration: 3.788E+03-1.91111E+05 CFU/ $\mathrm{m}^{3}$ ) than fungi (exposed-plate: 0-13 CFU/plate; impingement: 0-3.547E $+03 \mathrm{CFU} / \mathrm{m}^{3}$; filtration: $0-1.515 \mathrm{E}+04 \mathrm{CFU} /$ $\mathrm{m}^{3}$ ). Coagulase-negative Staphylococci and Micrococci were the predominant Gram-positive cocci in active and passive samples. Enterobacter and Pseudomonas were the predominant Gram-negative bacilli. Among fungi, Aspergillus niger was isolated throughout the year. There was no significant temporal variation in airborne microbial loads irrespective of methods.

Conclusions: Exposed-plate method was found to capture microorganisms efficiently with little variation in duplicate samples, suggesting its use in hospitals for preliminary assessment of indoor air quality and determine pathogenic microorganisms due to particle fall-out.

Key words: Indoor air, bioaerosols, hospital ward, tropical setting African Health Sciences 2012; 12(2): 217 - 225 http://dx.doi.org/10.4314/ahs.v12i2.22
\end{abstract}

\section{Introduction}

Indoor air quality in hospitals is a concern due to presence of airborne microorganisms that may cause nosocomial infections ${ }^{1}$. Few published reports have studied the seasonal fluctuations in microbial loads over time in hospital environment ${ }^{2,3}$. While studies in developing countries have documented presence of nosocomially significant bacteria and fungi in indoor air of healthcare facilities ${ }^{4,5,6}$, these studies were not performed over extended time periods to ascertain the influence of seasonal changes on airborne microbial loads.

\begin{tabular}{|l|}
\hline *Corresponding author: \\
Ms. Suchithra Sudharsanam \\
Research Scholar, CSIR - SRF \\
Sri Ramachandra Medical College \& Research \\
Institute \\
Sri Ramachandra University \\
Porur, Chennai 600116, India \\
Tel: +91-9841038575 \\
Fax: +91-44-24765995 \\
E-mail : suchisanam@gmail.com \\
\hline
\end{tabular}

African Health Sciences Vol 12 No 2 June 2012
Healthcare facilities are complex settings, especially in developing countries, where factors such as overcrowding, improper design and ventilation can impact the growth and / or survival of microorganisms. Climatic conditions such as excessive humidity and moisture of walls and ceilings may facilitate fungal colonisation. Physical parameters such as temperature and humidity are known to influence the ability of microorganisms to survive and be airborne ${ }^{7}$. In a tropical setting where hot and humid climatic conditions prevail, it is necessary to monitor airborne microbial concentrations and determine if there are variations in the microbial concentrations and their types with changing climatic conditions. This study was undertaken 1) to determine whether variation exists in microbial (aerobic bacterial and fungal) concentrations in indoor air of a hospital ward over a period of time, using active and passive methods and 2) to characterise the microorganisms present in indoor air. 


\section{Methods}

\section{Study design}

A prospective study was conducted to determine whether temporal variation exists in airborne microflora of a hospital ward. The study was carried out in a tertiary healthcare facility situated in West Chennai, India, for a period of one year from February 2008 to January 2009. Chennai is a city with tropical climate comprising of the following seasons, namely winter (January and February), pre-monsoon (March to May), south-west monsoon (June to September) and north-east monsoon (October to December) ${ }^{8}$.

Sampling months were randomly chosen and samples were collected between $15^{\text {th }}$ and $20^{\text {th }}$ days of the month. Following a detailed walkthrough, sampling location was identified as an orthopaedic ward provided with large windows for ventilation. Indoor and outdoor (control) air samples were collected in duplicates over different periods of the year by active and passive methods of sampling. Samples were analysed for type of microorganisms and their loads.

\section{Study area}

Based on the literature search and subsequent walkthrough, orthopaedic ward was chosen for the study, because orthopaedic patients are at greater risk for acquisition of nosocomial infections 9 . The ward under study was of the area $72 \mathrm{~m}^{2}$ with a capacity to accommodate upto seven patients. The ward was situated in the fourth floor of the building, surrounded by green vegetation. The room was provided with natural ventilation with windows supplemented by mechanical fans.

\section{Sample collection}

Walk-through was conducted prior to every sampling to gather details on the existing local environmental conditions and the extent of activity. Depending on the nature of the activity, the extent of activity was graded as minimum (talking), moderate (talking, movement of patients and delivering healthcare to patients) and maximum (talking, movement of patients, delivering healthcare to patients, and cleaning which includes change of bed linens and mopping of floors).

Air samples were collected simultaneously (in duplicates) by passive and active sampling methods. Outdoor samples were collected, in addition to indoor samples, as control for comparison of indoor microbial loads. Passive sampling was done using exposed-plate gravitational method ${ }^{10}$, by exposing media-containing plates for 30 minutes $^{11}$. Petri plates were put at a height of 60 - $70 \mathrm{~cm}$ above the ground level during sampling. Filter and impinger methods were the active sampling methods used in the study. Pumps were calibrated prior to sampling for accuracy in the rate of air sampling. Filter method was performed using personal sampler using filter cassettes loaded with gelatin filters (SKC Inc., USA) @ 3.5 L/min for 15 $\min ^{10,12}$, while impinger method involved use of biosampler (SKC Inc., USA) containing sterile phosphate buffered saline (PBS) @ 12.5 L/min for $20 \mathrm{~min}^{10,12}$. Ambient physical parameters, temperature and relative humidity were recorded. Media used for sampling were blood agar and MacConkey agar for aerobic bacteria, and Sabouraud's Dextrose agar for fungi (Hi Media Company Limited, India).

\section{Microbiological analysis of the air samples}

Gelatin filter (after air sampling) was allowed to digest in $10 \mathrm{~mL}$ of sterile PBS. The PBS from impinger and filter methods were subjected to further processing by concentration method for indoor samples and dilution method for outdoor samples. The samples were plated on $5 \%$ sheepBlood agar, MacConkey agar and Sabouraud's Dextrose agar. Both exposed plates and plates containing active samples were incubated aerobically at $37^{\circ} \mathrm{C}$ for $24-48 \mathrm{~h}$ for bacteria and at $25^{\circ} \mathrm{C}$ and $37^{\circ} \mathrm{C}$ upto 7 days for yeasts and moulds (since yeasts and yeast-like fungi grow best at $37^{\circ} \mathrm{C}$, and filamentous fungi grow at $25^{\circ} \mathrm{C}$, both temperatures were included in the study). Suitable tests were done for identification of microorganisms as per standard microbiological procedures. Bacterial isolates were observed for colony morphology and identified by Gram's staining and appropriate biochemical tests ${ }^{13,14}$. Filamentous fungi were identified by Lactophenol cottonblue staining and confirmed through Riddel's slide culture; yeast-like colonies were characterized by germ-tube test ${ }^{15}$. Candida was further speciated using tetrazolium reduction medium.

\section{Statistical analysis}

SPSS for Windows v. 11.5 package (SPSS Inc., USA) was used. Dependent variables were those of the different bioaerosol concentrations, while independent variables were the seasons, relative humidity and temperature. Pearsons' correlation coefficient was used to assess the correlation between samples collected in duplicates by the same method. 
A repeated-measure analysis of variance test (RMANOVA) was performed to determine the bioaerosols' distribution across seasons.

\section{Results}

A total of six sets of air samples were collected in different months over a period of one year, by active and passive methods from the same orthopaedic ward. Local climatic conditions were generally sunny irrespective of the sampling month. When the sampling months that were chosen for the study over different times of the year were analysed for the climatic conditions, they were found to be representative of the local prevailing seasons, namely winter (January and February), pre-monsoon (March to May), south-west monsoon (June to September) and north-east monsoon (October to December). The details of the seasons were obtained from the Regional Meteorological Centre, Chennai, India ${ }^{8}$.

Walk-through of the sampling location revealed no evidences of dampness or visible microbial growth in the walls. Activity in the ward was moderate to maximum during sampling, and included mopping of floor, movement of the patients, and talking. Ambient physical parameters such as temperature and relative humidity were recorded at the time of sampling (table 1).

Table 1: Ambient physical parameters at the sampling location

\begin{tabular}{|c|c|c|c|c|c|c|c|}
\hline S. NO. & Sampling month & Sampling & Temperature & Relative & & umber & \\
\hline & & session & $\left({ }^{\circ} \mathrm{c}\right)$ & humidity (\%) & beds & patients & occupants \\
\hline 1 & March 2008 & Forenoon & 27.2 & 69 & 7 & 7 & 18 \\
\hline 2 & April 2008 & Forenoon & 31.2 & 73 & 7 & 6 & 13 \\
\hline 3 & July 2008 & Forenoon & 31.8 & 71 & 7 & 5 & 11 \\
\hline 4 & September 2008 & Afternoon & 32.5 & 51 & 7 & 4 & 10 \\
\hline 5 & December 2008 & Forenoon & 26.3 & 72 & 7 & 7 & 15 \\
\hline 6 & January 2009 & Forenoon & 29.1 & 57 & 7 & 4 & 10 \\
\hline
\end{tabular}

Temperature was found to range between $26.3{ }^{\circ} \mathrm{C}$ and $32.5^{\circ} \mathrm{C}$, with maximum and minimum being recorded in the months of September and December respectively. Relative humidity was found to vary between $51 \%$ and $73 \%$ where maximum and minimum were documented in the months of April and September respectively. Number of patients ranged from four (September and January) to seven (March and December). Number of occupants (other than patients) was found to range from 10 to 18 . When the data on microbial loads in indoor air were compared with that of the control outdoor samples, it was found that microbial loads in indoor air were less than that of the outdoor air irrespective of the sampling month (data not shown).
Airborne microbial loads obtained from exposed plate method Airborne microbial loads

The airborne loads of total culturable bioaerosols ranged from 59 - $156 \mathrm{CFU} /$ plate (table 2), with peak values in December and lowest values in April. Airborne culturable bacteria ranged from $45-150$ $\mathrm{CFU} /$ plate. Their loads remained higher from December to March, with peak values being recorded in December. A sudden drop was observed in their loads in April, recording the least value, and remained low till September. Fungal loads ranged from 0 $13 \mathrm{CFU} /$ plate, the maximum being observed in April and minimum in March. 
Table 2 : Concentrations of aerobic bacteria and fungi in indoor air of a hospital ward

\begin{tabular}{|c|c|c|c|c|c|c|c|c|}
\hline \multicolumn{2}{|c|}{$\begin{array}{c}\text { S. NO. Sampling } \\
\text { month }\end{array}$} & \multirow[t]{3}{*}{$\begin{array}{l}\text { Media } \\
\text { used }\end{array}$} & \multicolumn{2}{|c|}{ Passive method } & \multicolumn{2}{|c|}{ Active method } & & \\
\hline & & & \multicolumn{2}{|c|}{$\begin{array}{l}\text { Exposed plate method } \\
\text { (CFU/plate) }\end{array}$} & \multicolumn{2}{|c|}{$\begin{array}{l}\text { Filter method } \\
\left(\mathrm{CFU} / \mathrm{m}^{3}\right)\end{array}$} & \multicolumn{2}{|c|}{$\begin{array}{l}\text { Impinger method } \\
\left(\mathrm{CFU} / \mathrm{m}^{3}\right)\end{array}$} \\
\hline & & & Sample 1 & Sample 2 & Sample 1 & Sample 2 & Sample 1 & Sample 2 \\
\hline \multirow[t]{3}{*}{1} & March 2008 & $\mathrm{BA}$ & 120 & 105 & $1.911 \mathrm{E}+05$ & $1.911 \mathrm{E}+055$ & $5.619 \mathrm{E}+04$ & $5.619 \mathrm{E}+04$ \\
\hline & & MCA & 2 & 1 & 0 & 0 & 0 & 0 \\
\hline & & SDA & 1 & 0 & $6.313 \mathrm{E}+02$ & 0 & 0 & 0 \\
\hline \multirow[t]{3}{*}{2} & April 2008 & $\mathrm{BA}$ & 50 & 45 & $7.576 \mathrm{E}+04$ & $2.841 \mathrm{E}+04$ & $7.84 \mathrm{E}+04$ & $1.307 \mathrm{E}+04$ \\
\hline & & MCA & 2 & 1 & 0 & 0 & 0 & 0 \\
\hline & & $\mathrm{SDA}$ & 13 & 13 & $4.419 \mathrm{E}+03$ & $1.894 \mathrm{E}+03$ & $2.8 \mathrm{E}+03$ & $3.547 \mathrm{E}+03$ \\
\hline \multirow[t]{3}{*}{3} & July 2008 & $\mathrm{BA}$ & 70 & 68 & $9.634 \mathrm{E}+04$ & $1.541 \mathrm{E}+04$ & $7.28 \mathrm{E}+04$ & $2.128 \mathrm{E}+04$ \\
\hline & & MCA & 2 & 3 & 0 & 0 & 0 & 0 \\
\hline & & SDA & 10 & 8 & $7.707 \mathrm{E}+03$ & $1.927 \mathrm{E}+03$ & $2.24 \mathrm{E}+03$ & $31.68 \mathrm{E}+03$ \\
\hline \multirow[t]{3}{*}{4} & Sept 2008 & $\mathrm{BA}$ & 90 & 92 & $1.231 \mathrm{E}+05$ & $3.788 \mathrm{E}+03$ & $6.72 \mathrm{E}+0$ & $41.12 \mathrm{E}+03$ \\
\hline & & MCA & 2 & 5 & 0 & 0 & 0 & 0 \\
\hline & & SDA & 8 & 1 & $1.515 \mathrm{E}+04$ & $3.788 \mathrm{E}+03$ & 0 & 0 \\
\hline \multirow[t]{3}{*}{5} & Dec 2008 & $\mathrm{BA}$ & 150 & 120 & $8.285 \mathrm{E}+04$ & $42.505 \mathrm{E}+04$ & $1.686 \mathrm{E}+05$ & $51.96 \mathrm{E}+04$ \\
\hline & & MCA & 4 & 0 & 0 & 0 & 0 & 0 \\
\hline & & $\mathrm{SDA}$ & 2 & 4 & $6.707 \mathrm{E}+03$ & $8.707 \mathrm{E}+03$ & 0 & $1.12 \mathrm{E}+03$ \\
\hline \multirow[t]{3}{*}{6} & January 2009 & $\mathrm{BA}$ & 100 & 110 & $6.898 \mathrm{E}+04$ & $8.898 \mathrm{E}+04$ & $4.16 \mathrm{E}+03$ & $5.72 \mathrm{E}+03$ \\
\hline & & MCA & 0 & 0 & $1.881 \mathrm{E}+03$ & $3.762 \mathrm{E}+03$ & $32.08 E+03$ & $3 \quad 5.2 \mathrm{E}+02$ \\
\hline & & SDA & 5 & 6 & 0 & 0 & $1.04 \mathrm{E}+03$ & $1.04 \mathrm{E}+03$ \\
\hline
\end{tabular}

BA - Blood agar $\quad$ MCA - MacConkey agar

SDA - Sabouraud Dextrose agar

\section{Statistical significance}

Airborne microbial loads obtained by passive method with an exposure for 30 minutes were found to vary with sampling months (Figure 1a), but was found to be statistically insignificant. There was little variation within the samples collected in duplicates, with strong correlation $(89.7 \%$ with a statistical significance of $\mathrm{p}=0.01)$.

Figure 1a: Pattern of variation in indoor microbial loads obtained using exposed plate method

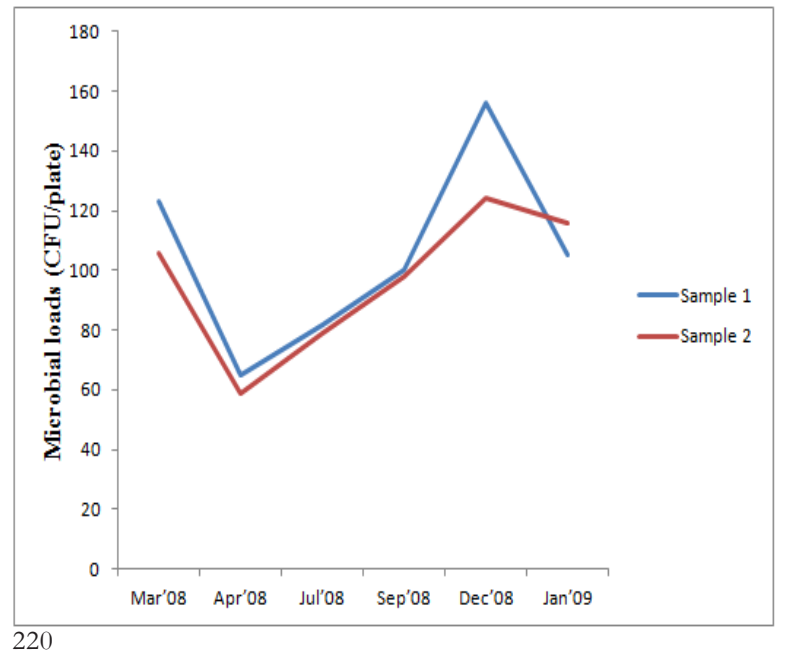

\section{Microorganisms isolated}

Microorganisms were isolated throughout the year; their loads however varied with different months (table 3). Loads of Gram-positive cocci (GPC) were higher than Gram-negative bacilli (GNB). Coagulasenegative Staphylococci (CNS) and Micrococci were predominantly isolated throughout the sampling period. Enterobacter and Pseudomonas were the frequently recovered GNB. Aspergillus sp. was the predominantly isolated fungi, of which Aspergillus niger was recovered throughout the study. In addition, Aspergillus fumigatus, Aspergillus flavus, and Absidia sp. were also isolated from indoor air.

\section{Airborne microbial loads obtained from impinger method}

\section{Airborne microbial loads}

The concentrations of total culturable bioaerosols obtained by impinger method ranged from $1.12 \mathrm{E}+03-1.6856 \mathrm{E}+05 \mathrm{CFU} / \mathrm{m}^{3}$ (table 2), with peak values in December and lowest values in September. Concentrations of airborne culturable bacteria also ranged from $1.12 \mathrm{E}+03-1.6856 \mathrm{E}+05$ $\mathrm{CFU} / \mathrm{m}^{3}$ since fungi were not recovered in these 
instances, the highest being in December and the lowest in September. Fungal concentrations ranged from $0-3.547 \mathrm{E}+03 \mathrm{CFU} / \mathrm{m}^{3}$, the maximum being observed in April and minimum in March and September.

\section{Statistical significance}

Though the concentrations of microorganisms between samples were found to vary with sampling months (figure 1b); it was found to be statistically insignificant, and the correlation between the two samples (collected in duplicates) was found to be not satisfactory $(7.3 \%)$.

Figure 1b : Pattern of variation in indoor microbial concentrations obtained using impinger method

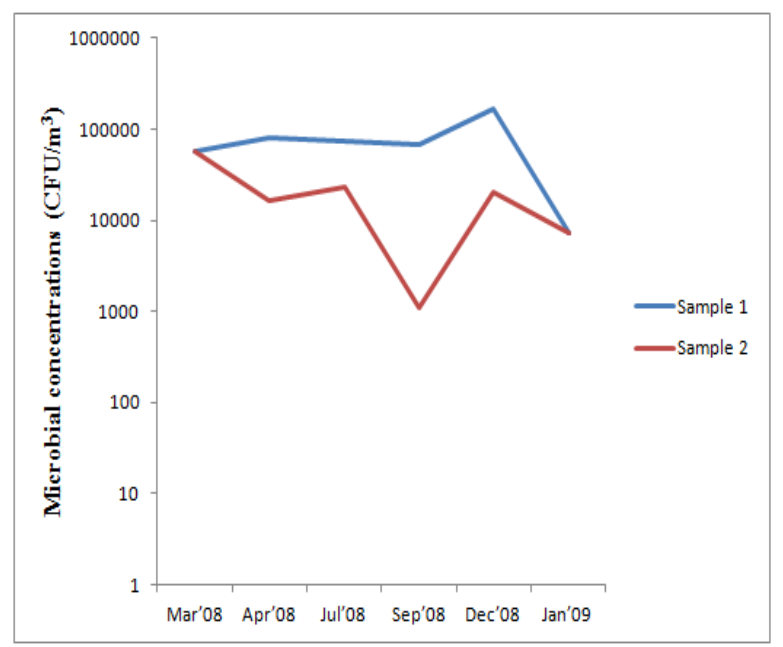

\section{Microorganisms isolated}

Microorganisms were recovered throughout the sampling period. GPC were isolated in higher concentrations, of which CNS and Micrococci were predominant (Table 3). Among GNB, Enterobacter sp. was the only isolate obtained in the month of January. Fungi were isolated in the months of April, July, December and January; Aspergillus niger, Aspergillus fumigatus and Aspergillus terreus were the commonly recovered species.

\section{Airborne microbial loads obtained from filter method}

Airborne microbial loads

Isolation of total culturable bioaerosols by filter method ranged from 7.576E+03 - 1.91724E+05 $\mathrm{CFU} / \mathrm{m}^{3}$ (table 2), with peak values in March and lowest in September. Airborne concentrations of culturable bacteria ranged from $3.788 \mathrm{E}+03-$
1.91111E $+05 \mathrm{CFU} / \mathrm{m}^{3}$, maximum being recovered in March, and minimum in September. Concentration of airborne fungi ranged from $0-1.515 \mathrm{E}+04$ $\mathrm{CFU} / \mathrm{m}^{3}$, with peak values in September and lowest values in January.

\section{Statistical significance}

There were fluctuations in recovery of microorganisms (Figure 1c), and the temporal variation in microbial concentrations was found to be statistically insignificant. Though there was a correlation $(60.5 \%)$ between the samples collected in duplicates, it was found to be statistically insignificant.

Figure 1c: Pattern of variation in indoor microbial concentrations obtained using filter method

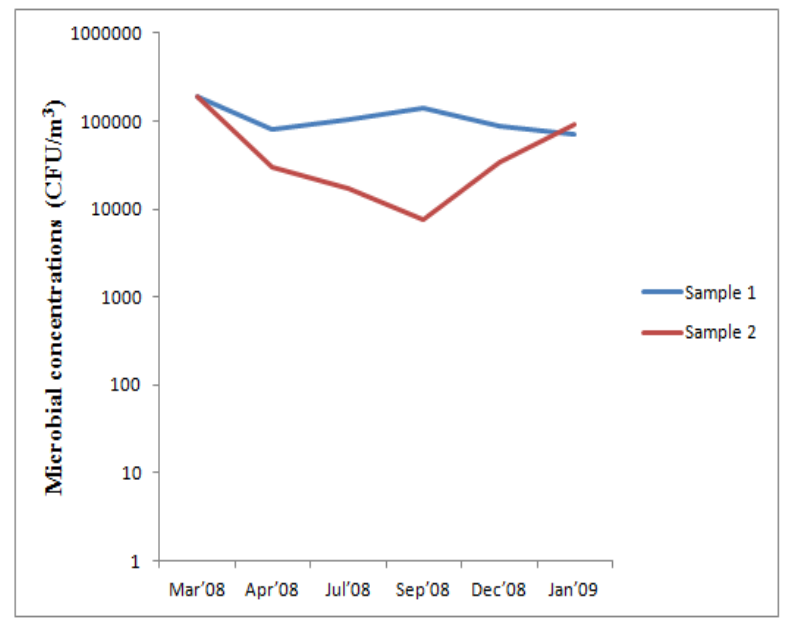

\section{Microorganisms isolated}

Recovery of microorganisms was documented throughout the study. High concentrations of GPC were recovered from air, of which CNS and Micrococci were frequently isolated (table 3). GNB was isolated only in the month of January, the isolate being Enterobactersp. Fungi were isolated throughout the study except the month of January; Aspergillus niger and Aspergillus fumigatus were frequently recovered. 
Table 3: Aerobic bacteria and fungi isolated from indoor air of a hospital ward during different months of a year

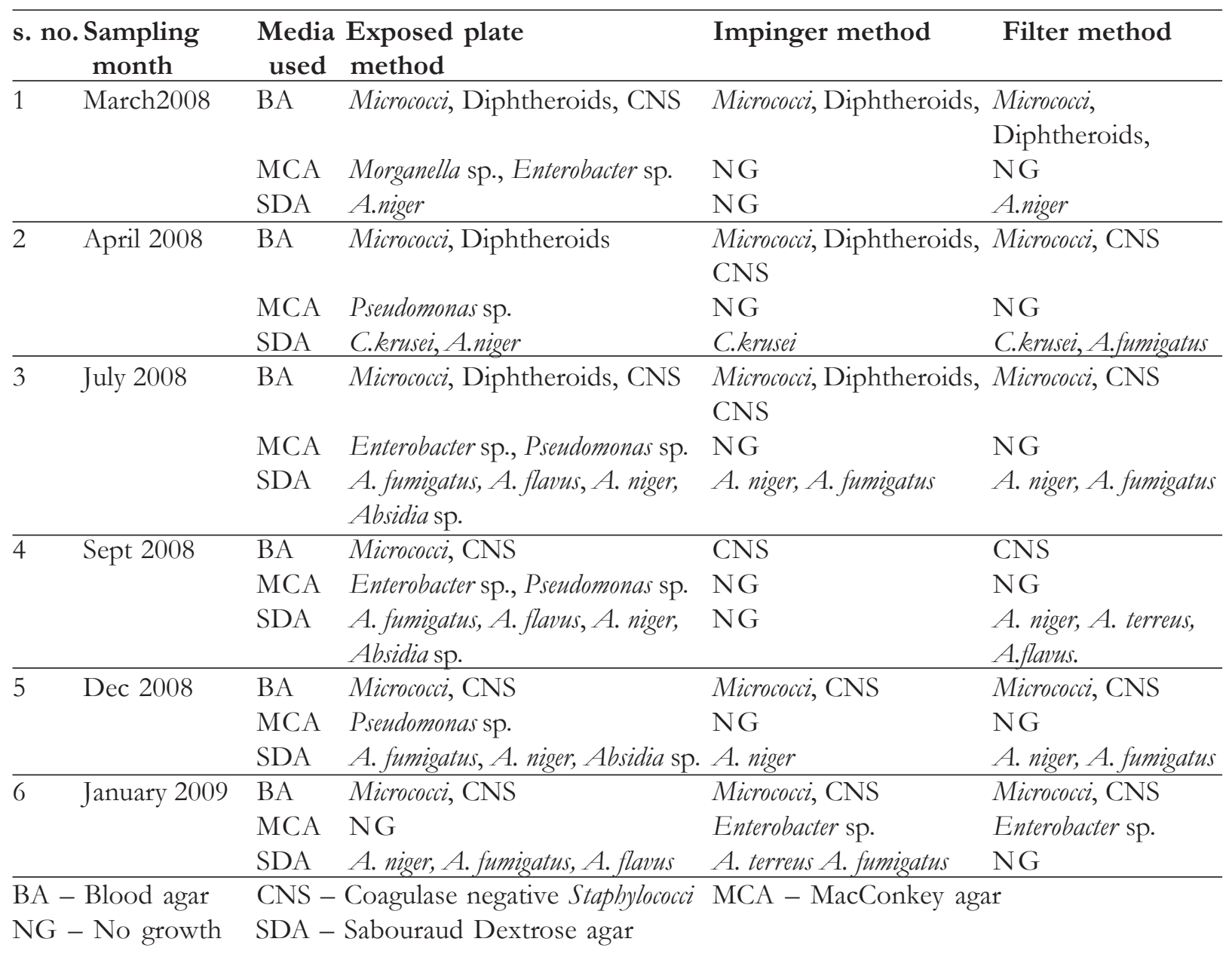

\section{Discussion}

Reports have previously documented the existence of microorganisms in hospital environments, including air and the possibility of air as a source for nosocomial infections $s^{1,4,5,6}$. A study conducted in a hospital ward of a pneumonological department in Poland found seasonal variations in total microbial loads, with greater variation among fungi than bacteria; the study further documented that eventhough microbial loads were less in indoor air of hospital, there is possibility of asthma exacerbations in some patients because of the presence of Aspergillus fumigatus and other potentially pathogenic species ${ }^{2}$. Another study carried out in two haematological units of a French hospital documented seasonal variations in fungal loads, with fungal concentrations significantly lower in winter $\left(2.7-3.1 \mathrm{cfu} / \mathrm{m}^{3}\right)$ than in summer $\left(4.2-5.0 \mathrm{cfu} / \mathrm{m}^{3}\right)$ in both haematology units ${ }^{3}$.

There is however paucity in data on fluctuations in airborne microbial loads with changing seasons, especially in the context of a developing country with tropical climate where hot-humid conditions prevail. Additionally, hospital design also plays a major role, where improper / faulty design may lead to poor indoor air quality and microbial contamination. Environmental factors such as condensation during excessive rainfall might also contribute to increased concentrations of airborne microorganisms. Increasing adoption of airconditioning in the existing healthcare facilities without adherence to proper engineering controls to maintain temperature and relative humidity at desired levels may facilitate microbial growth. It is therefore essential to carry out location specific studies to develop infection prevention measures.

So far, to our knowledge, no long-term studies have been carried out in the context of a developing country with resource limitations. Although different active and passive methods of air sampling are available, no single method is 
considered efficient for recovery of microorganisms, or is ideal in every sampling situation ${ }^{10}$. The authors, therefore, decided to perform sampling using active (impinger and filter methods) and passive (exposedplate method) sampling methods for improved recovery of microorganisms.

GPC are usually recovered by active methods of sampling. GNB, however, may get destroyed due to forceful impingement of air samples or desiccation at the time of filtration of air samples. Although exposed-plate method is a passive method, previous studies have documented isolation of GNB using this method ${ }^{4,5}$, thereby, making it essential to include exposed-plate method for better recovery. Moreover, exposed plate method may be used especially for settings like healthcare facilities with less airborne microbial loads when compared to outdoor settings like agriculture and poultry farming, where airborne microbial loads are high and require active methods of air sampling. Choice of the media used in the study was made based on the availability of the resources. In the context of a healthcare facility, media such as blood agar, MacConkey agar and Sabouraud's Dextrose agar are readily available in the laboratory facilitating easier sampling at times of an investigation without delay.

\section{Temporal variation in airborne microbial loads}

A repeated measure sampling was done as it allows for an analysis that takes into account the unique microbial and meteorological conditions within the sampling location, which in turn allows for seasonal comparisons that are not influenced by how high or low the baseline is for the location ${ }^{16}$. A temporal variation in the airborne microbial loads was documented; however, there was no statistical significance in the variation captured by active and passive sampling methods. The lack of appreciable variation in the airborne microbial loads may be attributed to the inherent deficiencies in the method used for sampling. It was evident that though exposed plate method was a passive method of sampling, the variation within duplicate samples was very less and had a strong correlation of $89.7 \%$ with a statistical significance of $\mathrm{p}=0.01$; active methods, on the other hand, had huge variations within the duplicate samples with no statistical significance.

This study indicates that exposed plate is more suitable and appropriate for areas like healthcare facilities as compared to outdoor settings like agriculture and poultry farming, where microbial loads are comparatively high and require active sampling to determine the loads. Though exposed plate method is a passive method, where the volume of air being sampled is unknown, it can be preferred over other active methods of sampling because of its reproducibility and reliability. Moreover, this method is cost-effective, easy to carry out and does not require expertise. This method particularly finds its application in healthcare facilities as this enables to determine airborne pathogenic microorganisms, which can cause nosocomial infections such as wound infections due to particle fall-out. Volumetric samplers often measure the total number of microorganisms in the air, and therefore is an indirect measurement of the likely microbial contamination of a surface at risk through fallout ${ }^{17}$.

Given the advantages, use of exposed plate method has certain limitations. This method may not be appropriate to determine the relationship with inhalable microbial exposure levels. Moreover, since only a small fraction of microbial load is collected due to gravitational pull, many species could be missing and remain unidentified.

Sampling by active methods (filter and impinger) showed that the recovery of the microorganisms was not appreciable, and variation was found to be statistically not significant. The variation within the samples collected in duplicates was found to be huge and inconsistent, irrespective of the sampling method used. The fluctuation in the recovery of microorganisms may be attributed to the inherent deficiencies of these methods such as forceful impingement / desiccation, which may cause microbial cell damage thereby affecting the recovery of the Gram-positive / Gram-negative organisms.

\section{Comparison of indoor and outdoor microbial loads}

Microbial loads in indoor air were less than that of the outdoor air irrespective of the method used for isolation of the culturable bioaerosols. Pattern of indoor and outdoor isolates was similar. Whenever outdoor microbial loads increased, there was a corresponding increase in microbial loads of indoor air. This indicates that indoor microflora is influenced by outdoor environmental conditions. Isolation pattern of microbial loads from indoor and outdoor air was similar in both active and passive methods thereby validating the methodology used.

\section{Microbiological profile of the indoor air}

Microorganisms were isolated throughout the year 
with fluctuations in their loads with the sampling months or the changing seasons. Concentrations of GPC were very high than GNB. CNS and Micrococci were predominant in all seasons irrespective of the sampling method. Enterobacter and Pseudomonas were the predominant GNB. Exposed method was efficient in isolation of GNB; impinger and filter methods did not facilitate recovery of GNB during the study period except in the month of January. It was further observed that Pseudomonas sp. was isolated in summer and monsoon months, while Enterobacter was common in winter. Aspergillus niger fungi was isolated throughout the year irrespective of the method. Candida krusei was the only yeast isolated at the onset of summer (April).

High concentrations of GPC may be attributed to lower susceptibility of these organisms to environmental stress ${ }^{18}$. Other factors that may contribute are improper ventilation and presence of increased number of occupants beyond room capacities $^{19}$, as GPC are constantly shed from skin, clothing and hair. Though CNS were the predominant isolates, increasing incidences of nosocomial infections by CNS make it a cause for concern $^{20}$.

Isolation of GNB was occasional and in lower concentrations. One of the reasons may probably be their susceptibility to environmental stress $^{18}$. Pseudomonas sp. and Enterobacter sp. were the commonly isolated GNB. These organisms are often found to grow on moist surfaces. Their presence may be attributed to the presence of wash-room in the vicinity of the sampling area, which may provide moisture required for survival and growth ${ }^{21,22}$. Since both Pseudomonas sp. and Enterobacter sp. are known nosocomial agents, understanding of the hospital milieu is essential to identify the environmental conditions that favour the growth of these microorganisms. This will provide insights into aspects for proper designing and construction of hospitals and help to target preventive measures.

Though fungi were seen in few numbers, their mere existence in the hospital air is of concern. Species of Aspergillus have seen associated with incidences of nosocomial infections in immuno-compromised patients and children either as primary or secondary infections; apart from these infections, allergic reactions have also been reported following inhalation of fungal spores, making it essential to pay attention to their presence in hospital air $^{23,24}$.

This is the first study in a developing country with tropical climate, to our knowledge, 224 documenting variations in microbial loads in hospital indoor air through simultaneous air sampling using active and passive sampling methods. From this study, it is evident that in the context of a tropical setting, where hot and humid conditions prevail throughout the year irrespective of the prevailing seasons, changing climatic conditions may not have an impact on the airborne microbial concentrations.

The study was carried out with small number of samples due to resource limitations. Further longterm studies can be carried out to strengthen the study findings. This preliminary report is suggestive of the need for future studies comparing active and passive methods across different geographical regions in the context of developing countries.

Given the cost constraints, exposed plates can therefore be used in hospitals with fewer technical facilities for preliminary assessment of indoor air quality. Furthermore, exposed plate method can also be used to determine airborne pathogenic microorganisms, which can cause nosocomial infections such as wound infections due to particle fall-out.

\section{Conclusion}

Though there was temporal variation in the airborne microbial loads, the variation was found to be statistically insignificant irrespective of the sampling method used in the study. Exposed-plate method was found to capture microorganisms efficiently with little variation in duplicate samples, thereby suggesting its use in hospitals for preliminary assessment of indoor air quality and determine pathogenic microorganisms due to particle fall-out.

\section{Acknowledgement}

The Council of Scientific and Industrial Research (CSIR), India for providing partial financial assistance through the Senior Research Fellowship [09/949/ (0002)/2009/EMR - I] to carry out the research work.

\section{References}

1. Beggs CB. The Airborne Transmission of Infection in Hospital Buildings: Fact or Fiction? Indoor Built Environ 2003; 12: 9-18.

2. Augustowska M, Dutkiewicz J. Variability of airborne microflora in a hospital ward within a period of one year. Ann Agric Environ Med 2006; 13: 99-106.

3. Sautour M, Sixt N, Dalle F, L'Ollivier C, Fourquenet V, Calinon C, et al. Profiles and

African Health Sciences Vol 12 No 2 June 2012 
seasonal distribution of airborne fungi in indoor and outdoor environments at a French hospital. Sci Total Env 2009; 407: 3766-3771.

4. Sudharsanam S, Srikanth P, Sheela M, Steinberg R. Study of Indoor Air Quality in Hospitals in South Chennai, India - Microbial Profile. Indoor Built Environ 2008; 17: 435-441.

5. Ekhaise FO, Ighosewe OU, Ajakpovi OD. Hospital Indoor Airborne Microflora in Private and Government Owned Hospitals in Benin City, Nigeria. World J Med Sci 2008; 3: 19-23.

6. Qudiesat K, Abu-Elteen K, Elkarmi A, Hamad M, Abussaud M. Assessment of airborne pathogens in healthcare settings. Afr J Microbiol Res 2009; 3: 66-76.

7. Stetzenbach LD. Introduction to Aerobiology; in Hurst CJ, Crawford RL, Knudsen G, McInerney M, Stetzenbach LD (eds): Manual of Environmental Microbiology, ed 2. ASM Press, Washington DC, 2002, pp 801-813.

8. Regional Meteorological Centre, Chennai Seasons. Available at: http:// www.amsschennai.gov.in/Seasons.html [last accessed on 2012 April 12].

9. Onipede AO, Oluyede CO, Aboderin AO, Zailani SB, Adedosu AM, Oyelese AO et al. A survey of hospital acquired infections in Obafemi Awolowo University teaching hospital, ILE-IFE. Afr J Clin Exper Microbiol 2004; 5: 108118.

10. Macher JM, Streifel AJ, Vesley D. Problem buildings, Laboratories and Hospitals; in Cox CS and Wathes CM (eds): Bioaerosols handbook. Lewis publishers, New York, 1995, pp 505-530.

11. Sudharsanam S, Srikanth P, Krishnamurthy S, Steinberg R. Microorganisms in Bioaerosols in Indoor Air of Hospital and Non-hospital Settings. Sri Ramachandra Journal of Medicine 2009; 2: 52 .

12. SKC Personal Sampling Pump - Universal XR Pump Model PCXR8 (5 to $5000 \mathrm{ml} / \mathrm{min}$ ). Available at : http://www.skcinc.com/pumps/ 224-PCXR8.asp [last accessed on 2012 April 12].

13. Collee JG, Fraser AG, Marmion BP, Simmons A. Mackie and McCartney Practical Medical Microbiology, ed 14. Churchill Livingstone publications, New York, 1999, pp 135-150.
14. Baron EJ, Peterson LR, Finegold SM. Bailey and Scott's Diagnostic Microbiology, ed 9. MosbyYear Book, St Louis, 1994, pp 321-352, 362428, 457-465.

15. Barnett HL, Hunter BB. Illustrated Genera of Imperfect Fungi, ed 4. APS Press, The American Phytopathological Society, St Paul, 1999.

16. Mota LC, Gibbs SG, Green CF, Payan F, Tarwater PM, Ortiz M. Characterization of seasonal indoor and outdoor bioaerosols in the arid environment of El Paso, Texas. J Environ Health 2008; 70: 48-53.

17. Pasquarella C, Pitzurra O, Savino A. The index of microbial air contamination. J Hosp Infect 2000; 46: 241-256.

18. Borriello PS, Murray PR, Funke G. Topley and Wilson's Microbiology and Microbial Infections: Bacteriology-I, ed 10., American Society for Microbiology Press, Washington DC, 2005, pp 185-194.

19. Ayliffe GAJ, Babb JR, Taylor LJ. Infection and the spread of micro-organisms; in Hospital Acquired Infections: Principles and prevention, ed 3. Butterworth Heinemann publications, Oxford, 1999, pp 38.

20. von Eiff C, Proctor RA, Peters G. Coagulasenegative staphylococci. Pathogens have major role in nosocomial infections. Postgrad Med 2001; 110:63-4, 69-70, 73-76.

21. Rughooputh $\mathrm{S}$. The role of Pseudomonas aeruginosa in nosocomial infections: Biomedical scientist 2001.

22. Banerjee G, Ayyagari A, Prasad KN, Dhole TN, Singh SK. Nosocomial infection due to Enterobacter cloacae in a tertiary care hospital in northern India. Indian J Med Res 1996; 103: 5861.

23. Lugauskas A. Filamentous Fungi Isolated in Hospitals and Some Medical Institutions in Lithuania. Indoor Built Environ 2004; 13: 101-108.

24. Srikanth P, Sudharsanam S, Steinberg R. Bioaerosols in Indoor Environments Composition, Health Effects and Analysis. Indian J Med Microbiol 2008; 26: 302-312 